\title{
Uruburuella suis gen. nov., sp. nov., isolated from clinical specimens of pigs
}

\author{
A. I. Vela, ${ }^{1}$ M. D. Collins, ${ }^{2}$ P. A. Lawson, ${ }^{2}$ N. García, ${ }^{1}$ L. Domínguez ${ }^{1}$ \\ and J. F. Fernández-Garayzábal ${ }^{1}$ \\ 'Departamento de Patología Animal I (Sanidad Animal), Facultad de Veterinaria, Universidad \\ Complutense, 28040 Madrid, Spain \\ ${ }^{2}$ School of Food Biosciences, University of Reading, Reading RG6 6AP, UK
}

Correspondence

J. F. Fernández-Garayzábal garayzab@vet.ucm.es
The family Neisseriaceae was proposed by Prévot in 1933. As circumscribed by Bøvre (1984), it accommodated a group of Gram-negative, oxidase- and catalase-positive, aerobic or facultatively anaerobic, non-spore-forming, rodor coccoid-shaped organisms and embraced four genera: Neisseria, Kingella, Acinetobacter and Moraxella (Bøvre, 1984). The family Neisseriaceae has undergone various revisions over the years, and numerous other genera have been assigned to it [e.g. Psychrobacter (Juni \& Heym, 1986), Mesophilobacter (Nishimura et al., 1989), Alysiella (Rossau et al., 1989) and Eikenella and Simonsiella (Dewhirst et al., 1989)]. On the basis of rRNA cistron similarity studies, Rossau et al. (1986) recommended that the genera Acinetobacter, Moraxella and Branhamella be excluded from the family Neisseriaceae. Subsequent studies by Rossau et al. (1989) showed that the genera Neisseria, Kingella, Eikenella, Simonsiella and Alysiella were closely related and should be classified together in the family Neisseriaceae, which comprises a major branch of the $\beta$-Proteobacteria. Comparative 16S rRNA gene sequencing studies by Dewhirst et al. (1989) confirmed the results of Rossau et al. (1989) and led to the recommendation that the genera Eikenella and Simonsiella be transferred to the family Neisseriaceae. In

Published online ahead of print on 29 October 2004 as DOI 10.1099/ ijs.0.63346-0.

The GenBank/EMBL/DDBJ accession number for the 16S rRNA gene sequence of strain CCUG $47806^{\top}$ is AJ586614.

An extended dendrogram including a wider sample of reference species is available as a supplementary figure in IJSEM Online. recent years, other genera, e.g. Laribacter (Yuen et al., 2001) and Microvirgula (Patureau et al., 1998), have been described and assigned to the family Neisseriaceae.

Organisms within the family Neisseriaceae can be isolated from a range of environmental sources (Moss \& Bryant, 1982) as well as from different human and animal mucosal surfaces (Kuhn, 1981; Snell, 1984). Only two species, Neisseria gonorrhoeae and Neisseria meningitidis, are wellestablished human pathogens (Morse \& Knapp, 1991). Other species of the Neisseriaceae have been implicated as opportunistic human pathogens in a number of different clinical processes (Wong \& Janda, 1992; Dolter et al., 1998). In veterinary medicine, too, neisseriae have been implicated as pathogens in a number of different clinical processes (Elad et al., 1990; Yeruham et al., 2001). In this study, we have characterized five Neisseria-like organisms isolated from the heart and lungs of pigs with respiratory infections. On the basis of phenotypic and molecular taxonomic evidence, we present the description of a novel genus and species within the family Neisseriaceae, for which we propose the name Uruburuella suis gen. nov., sp. nov.

The bacterial strains were isolated from the lungs (strains $1258 / 02^{\mathrm{T}}$ and 221/01) and hearts (strains 959/02, 1039/02 and 238/01) of different animals with lesions of pneumonia and pericarditis, respectively. The pigs were between 5 and 6 months old and were kept under intensive management conditions. Samples from affected zones of lung and heart were collected under aseptic conditions and kept under refrigeration until being processed in the laboratory (within 
$6 \mathrm{~h})$. Strains were isolated on Columbia blood agar plates (bioMérieux) and incubated for $24 \mathrm{~h}$ at $37^{\circ} \mathrm{C}$ under aerobic and anaerobic conditions. The strains were biochemically characterized using the API 20NE, API NH and API ZYM systems (bioMérieux) according to the manufacturer's instructions. The production of DNase was determined on DNA medium (bioMérieux). Fatty acid methyl esters were prepared and analysed as described by Kämpfer \& Kroppenstedt (1996). The G+C content of the DNA (mol\%) was determined by HPLC according to Mesbah et al. (1989). For $16 \mathrm{~S}$ rRNA gene sequence analysis, a large fragment (around 1450 bases) of the 16S rRNA gene of the isolates was amplified by using a PCR and was directly sequenced using a Taq DyeDeoxy terminator cycle sequencing kit (Applied Biosystems) and an automatic DNA sequencer (model 373A; Applied Biosystems). The nearest described relatives of the new isolates were determined by performing searches of GenBank using the program FASTA (Pearson, 1994). These closely related sequences were retrieved from GenBank and aligned with the newly determined sequences using the program DNATools (Rasmussen, 1995). A phylogenetic tree was reconstructed according to the neighbour-joining method (Saitou \& Nei, 1987), with the programs DNATools and TREEVIEW (Page, 1996), and the stability of the groupings was estimated by bootstrap analysis (1000 replications).

The five unidentified isolates consisted of Gram-negative, non-motile, non-spore-forming, coccobacillus-shaped cells. The organisms were facultatively anaerobic and catalaseand oxidase-positive. When cultured aerobically on Columbia blood agar plates, the isolates formed small colonies (approx. 1-2 $\mathrm{mm}$ diameter, after $24 \mathrm{~h}$ incubation at $37^{\circ} \mathrm{C}$ ) that were circular, smooth, entire, non-haemolytic and yellowpigmented. They did not grow on MacConkey or ThayerMartin agars. Swimming motility was absent. In the miniaturized biochemical kits, the isolates displayed very similar, though not identical, phenotypic profiles. All of the isolates reduced nitrate and nitrite, produced acid from glucose and fructose and gave a positive reaction for proline arylamidase. All isolates gave negative results in the tests for indole production, hydrolysis of gelatin and aesculin, arginine dihydrolysis and ornithine decarboxylation. Three of the five strains $\left(1258 / 02^{\mathrm{T}}, 959 / 02\right.$ and 1039/02) hydrolysed urea. None of the isolates produced acid from sucrose or maltose. Assimilation of glucose, arabinose, mannitol, gluconate and malate was observed, but citrate, maltose, caprate, phenylacetate and adipate were not assimilated. Two strains (221/01 and 238/01) did not assimilate mannose. Using the API ZYM system, positive reactions for esterase C4, ester lipase C8, leucine arylamidase and acid phosphatase, and a weak reaction for alkaline phosphatase, were detected. All other tests were negative. In terms of their overall cellular morphology and biochemical characteristics, the unidentified isolates somewhat resembled members of the family Neisseriaceae. To clarify the association of the unknown pig isolates with the family Neisseriaceae, two representative strains, $1258 / 02^{\mathrm{T}}$ and $959 / 02$, were subjected to cellular fatty acid analysis. The cellular lipid composition of the isolates was characterized by the absence of branched fatty acids, which is consistent with their classification in the family Neisseriaceae (Bøvre, 1984). The major fatty acids of the strains were C16: 1 cis-9, C16:0 and $\mathrm{C} 18: 1$ cis-11 (mean amounts, 30.6, 33.9 and 17.9\%, respectively). The isolates also contained moderate or small amounts of $\mathrm{C} 12: 0(6 \cdot 1 \%), 3-\mathrm{OH} \mathrm{C} 12: 0(4 \cdot 2 \%), \mathrm{C} 14: 0$ ( $2 \cdot 3 \%), 3-\mathrm{OH}$ C14:0 (1.6\%), C18:2 cis-9 (1.3\%) C18:0 (0.7\%), C16: 1 cis-7 (0.6\%) and C18: 1 cis-9 (0.6\%).

To determine the phylogenetic position of the unknown isolates, their $16 \mathrm{~S}$ rRNA gene sequences were determined by direct sequencing of in vitro-amplified rRNA gene products. The sequence of a large fragment ( >1400 nt) from strains $1258 / 02^{\mathrm{T}}$ and $959 / 02$, and approximately $1000 \mathrm{nt}$ of the other three strains were determined; comparative analysis revealed 99.9-100\% 16S rRNA gene sequence similarity among the strains, thereby demonstrating high genealogical homogeneity. Sequence searches of GenBank showed that the isolates were most closely related to species of the family Neisseriaceae (data not shown). The pig isolates exhibited similar levels of sequence similarity with Neisseria (approx. 92-96\%), Simonsiella (94-95\%), Kingella (94$95 \%)$, Alysiella (94\%) and Eikenella (94\%) species. It is pertinent to note that the five isolates possessed an adenine and a uracil at positions 585 and 756, respectively (numbering relative to the Escherichia coli sequence), in their 16S rRNA. These signatures are characteristic of members of the family Neisseriaceae (Dewhirst et al., 1989). Treeing analysis confirmed this affinity, and the unknown bacterium (as exemplified by strain $1258 / 02^{\mathrm{T}}$ ) formed a distinct subline within a large rRNA cluster that included the genera Neisseria, Kingella, Alysiella, Eikenella and Simonsiella. Bootstrap resampling analysis, however, showed that the unknown bacterium did not possess significant affinity with any recognized species. A dendrogram depicting the phylogenetic relationships of the unidentified bacterium is shown in Fig. 1.

The family Neisseriaceae comprises a major branch of the $\beta$-Proteobacteria. Phylogenetically, the family encompasses the genera Neisseria, Kingella, Eikenella, Simonsiella and Alysiella (Dewhirst et al., 1989; Rossau et al., 1989). It is clear from the results of the present study that the unidentified bacterium from pigs is phylogenetically a member of this family grouping. Phylogenetically, the pig bacterium forms a distinct subline and does not display a close relationship with any described organism (Fig. 1). The generic placement of the unidentified bacterium is problematic given the phylogenetic intermixing of some species of the genera Neisseria, Kingella, Eikenella and Simonsiella. Upon treeing analysis, the swine bacterium displays a loose association with Neisseria canis, although this relationship was not supported by bootstrap resampling. Species currently assigned to the genus Neisseria are phylogenetically not homogeneous, although some Neisseria species form a robust cluster with $N$. gonorrhoeae, the type species of the 


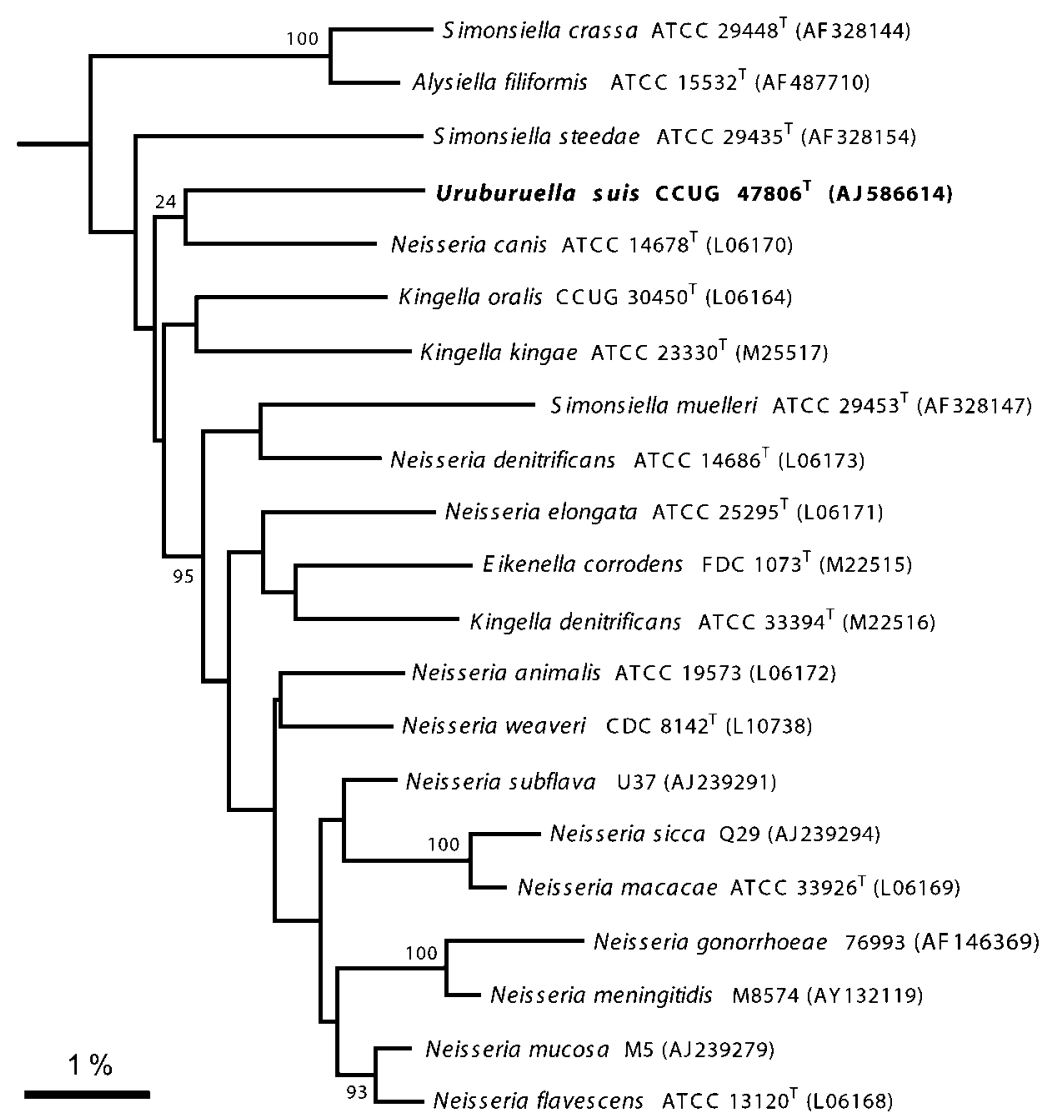

Fig. 1. Unrooted tree based on $16 \mathrm{~S}$ rRNA showing the phylogenetic relationships of $U$. suis $\mathrm{sp}$. nov. Bootstrap values (each expressed as a percentage of 1000 replications) are given at branching points. A full version of the dendrogram, including a wider sample of Streptococcus species, is available as a supplementary figure in IJSEM Online. Bar, $1 \%$ sequence divergence. genus. The unidentified pig bacterium, however, is far removed from N. gonorrhoeae and its close relatives and therefore cannot be considered a legitimate member of this genus. The unknown bacterium also fails to display specific phylogenetic affinities with other related genera (Alysiella, Kingella, Eikenella and Simonsiella) within the Neisseriaceae. Support for the separateness of the unknown bacterium is also evident from phenotypic considerations. The pig bacterium is similar to Eikenella species and some Kingella species in being facultatively anaerobic, but differs markedly from species of the genera Neisseria, Alysiella and Simonsiella, which are strictly aerobic. However, the unknown bacterium is catalase-positive, whereas members of the genera Eikenella and Kingella are catalase-negative. Similarly, the unknown bacterium differs further from members of the genera Eikenella and Kingella in not displaying twitching motility. The coccobacillus-shaped pig bacterium can also be readily distinguished from species of the genera Alysiella and Simonsiella, which form flat multicellular filaments (which may reach $2-10 \mu \mathrm{m}$ in width and $50 \mu \mathrm{m}$ or more in length and possess bilateral symmetry). Members of the latter two genera also display gliding motility, which is absent in the unidentified bacterium. Given these phenotypic differences and the distinct phylogenetic subline formed by the pig bacterium, we consider that this organism merits classification in a novel genus within the Neisseriaceae. The five isolates showed very high $16 \mathrm{~S}$ rRNA gene sequence relatedness, as well as relatively uniform morphological and biochemical characteristics, which, together with their recovery from similar sources, is consistent with them/their belonging to a single species. Therefore, on the basis of the relatively high homogeneity of the isolates and their distinctiveness from other members of the Neisseriaceae, we propose that these organisms from pigs be classified as Uruburuella suis gen. nov., sp. nov. Tests that are useful in distinguishing Uruburuella from other closely related genera are shown in Table 1.

\section{Description of Uruburuella gen. nov.}

Uruburuella (U.ru.bu.ru.el'la. L. dim. ending - ella; N.L. fem. dim. n. Uruburuella in memory of the Spanish microbiologist Federico Uruburu, for his contributions to the promotion and strengthening of the Spanish Type Culture Collection).

Cells are Gram-negative, non-spore-forming, non-motile coccobacilli. Facultatively anaerobic and catalase- and oxidase-positive. Non-diffusible yellow pigments are produced. Grows in 3\%(w/v) NaCl. Produces acid from glucose and some other sugars. Reduces nitrate and nitrite. Long-chain fatty acids are of the straight-chain saturated and monounsaturated types, with $\mathrm{C} 16: 0, \mathrm{C} 16: 1$ cis-9 and C18: 1 cis-11 predominating. The $\mathrm{G}+\mathrm{C}$ content of the DNA of the type species is $55 \mathrm{~mol} \%$. The genus Uruburuella is a member of the family Neisseriaceae in the $\beta$-subclass of the 
Table 1. Characteristics that differentiate Uruburuella gen. nov. from its closest phylogenetic relatives

Taxa: 1, Uruburuella suis gen. nov., sp. nov.; 2, Neisseria; 3, Kingella; 4, Eikenella; 5, Simonsiella; 6, Alysiella. Data for reference genera were obtained from Vedros (1984), Jackson \& Goodman, (1984), Larkin (1989), Morse \& Knapp (1991), Dewhirst et al. (1993), Barrett \& Sneath (1994) and Hedlund \& Staley (2002). Symbols: + , positive; -, negative; V, variable; ND, not determined.

\begin{tabular}{|c|c|c|c|c|c|c|}
\hline Characteristic & 1 & 2 & 3 & 4 & 5 & 6 \\
\hline \multicolumn{7}{|l|}{ Cell morphology } \\
\hline Cocci & - & + & - & - & - & - \\
\hline Rods & + & + & + & + & $+^{*}$ & $+^{*}$ \\
\hline Facultatively anaerobic & + & - & + & + & - & - \\
\hline Catalase production & + & $+{ }^{a} \dagger$ & - & - & + & + \\
\hline Twitching motility & - & $-{ }^{b}$ & + & + & - & - \\
\hline Gliding motility & - & - & - & - & + & + \\
\hline Growth in $3 \%(\mathrm{w} / \mathrm{v}) \mathrm{NaCl}$ & + & $--^{c}$ & - & ND & - & - \\
\hline Acid from glucose & + & $+{ }^{d}$ & + & - & $+^{e}$ & + \\
\hline Urease & $\mathrm{V}$ & - & - & - & - & - \\
\hline Nitrate reduction & + & $-{ }^{f}$ & $-g$ & + & $+{ }^{h}$ & - \\
\hline Nitrite reduction & + & $+{ }^{i}$ & $-g$ & - & $+{ }^{h}$ & - \\
\hline
\end{tabular}

* Simonsiella and Alysiella species form flat multicellular filaments that may reach $2-10 \mu \mathrm{m}$ in width and $50 \mu \mathrm{m}$ or more in length and possess bilateral symmetry.

$\dagger$ Discrepant results are indicated by: $a$, Neisseria elongata can be negative; $b, N$. gonorrhoeae and $N$. meningitidis may demonstrate twitching motility; $c, N$. canis, Neisseria animalis and Neisseria weaveri may show growth; $d, N$. canis, Neisseria ovis, Neisseria cuniculi, Neisseria caviae, Neisseria cinerea, Neisseria flavescens and $N$. elongata may be negative; $e$, Simonsiella steedae may be negative; $f, N$. canis, N. ovis, N. caviae and Neisseria mucosa may reduce nitrate; $g$, Kingella denitrificans may reduce nitrate and nitrite; $h$, Simonsiella muelleri may not reduce nitrate and/or nitrite; $i, N$. gonorrhoeae, $N$. canis, N. ovis, N. cuniculi and N. caviae may not reduce nitrite.

Proteobacteria. The type species of the genus is Uruburuella suis.

\section{Description of Uruburuella suis sp. nov.}

Uruburuella suis (su'is. L. fem. n. sus, suis pig, hog; L. gen. n. suis of the hog).

Displays the following properties in addition to those given in the genus description. Colonies are circular, yellowpigmented, smooth, entire and approximately 1-2 mm diameter on Columbia blood agar after $24 \mathrm{~h}$ incubation at $37^{\circ} \mathrm{C}$. Colonies are non-haemolytic. No growth occurs on MacConkey agar or Thayer-Martin agar. Aesculin and gelatin are not hydrolysed. Hydrolysis of urea is variable. Indole is not produced. Acid is produced from fructose and glucose but not from maltose or sucrose. Assimilation of glucose, arabinose, mannitol, gluconate and malate is observed but citrate, maltose, caprate, phenylacetate and adipate are not assimilated. Mannose may or may not be assimilated. Activity for alkaline phosphatase (weak reaction), ester lipase C8, esterase C4, leucine arylamidase, acid phosphatase and proline arylamidase is detected. Arginine dihydrolase, lipase $\mathrm{C} 14$, valine arylamidase, cystine arylamidase, trypsin, $\alpha$-chymotrypsin, naphtholAS-BI-phosphohydrolase, $\alpha$-glycosidase, $\beta$-galactosidase, $\beta$-glucuronidase, $\alpha$-glucosidase, $\beta$-glucosidase, $N$-acetyl$\beta$-glucosaminidase, $\alpha$-mannosidase, $\alpha$-fucosidase and ornithine decarboxylase are not produced.

Isolated from the lungs and heart of pigs with respiratory disease. The type strain is $1258 / 02^{\mathrm{T}}\left(=\right.$ CCUG $47806^{\mathrm{T}}=$ CECT $5685^{\mathrm{T}}$ ).

\section{Acknowledgements}

This work was supported by project AGL2003-08848-C02-01/GAN of the Spanish Ministry of Science and Technology. The authors thank K. Brownlee, L. Delgado and L. Cuesta for technical assistance.

\section{References}

Barrett, S. J. \& Sneath, P. H. A. (1994). A numerical phenotypic study of the genus Neisseria. Microbiology 140, 2867-2891.

Bøvre, K. (1984). Family VIII. Neisseriaceae Prévot 1933, $119^{\mathrm{AL}}$. In Bergey's Manual of Systematic Bacteriology, vol. 1, pp. 288-290. Edited by N. R. Krieg \& J. G. Holt. Baltimore: Williams \& Wilkins.

Dewhirst, F. E., Paster, B. J. \& Bright, P. L. (1989). Chromobacterium, Eikenella, Kingella, Neisseria, Simonsiella, and Vitreoscilla species comprise a major branch of the beta group Proteobacteria by $16 \mathrm{~S}$ ribosomal ribonucleic acid sequence comparison: transfer of Eikenella and Simonsiella to the family Neisseriaceae (emend.). Int J Syst Bacteriol 39, 258-266.

Dewhirst, F. E., Chen, C.-K. C., Paster, B. J. \& Zambon, J. J. (1993). Phylogeny of species in the family Neisseriaceae isolated from human dental plaque and description of Kingella orale sp. nov. Int J Syst Bacteriol 43, 490-499.

Dolter, J., Wong, J. \& Janda, J. M. (1998). Association of Neisseria cinerea with ocular infections in paediatric patients. J Infect 36, 49-52.

Elad, D., Shlomovitz, S., Bernstein, M. \& Bassan, J. (1990). Neisseria cuniculi in ruminants: epidemiological aspects. Epidemiol Infect 105, 559-563.

Hedlund, B. P. \& Staley, J. T. (2002). Phylogeny of the genus Simonsiella and other members of the Neisseriaceae. Int J Syst Evol Microbiol 52, 1377-1382.

Jackson, F. L. \& Goodman, Y. (1984). Genus Eikenella Jackson and Goodman 1972, 74 ${ }^{\mathrm{AL}}$. In Bergey's Manual of Systematic Bacteriology, vol. 1, pp. 591-597. Edited by N. R. Krieg \& J. G. Holt. Baltimore: Williams \& Wilkins.

Juni, E. \& Heym, G. A. (1986). Psychrobacter immobilis gen. nov., sp. nov.: genospecies composed of gram-negative, aerobic, oxidasepositive coccobacilli. Int J Syst Bacteriol 36, 388-391.

Kämpfer, P. \& Kroppenstedt, R. M. (1996). Numerical analysis of fatty acid patterns of coryneform bacteria and related taxa. Can J Microbiol 42, 989-1005.

Kunn, D. A. (1981). The genera Simonsiella and Alysiella. In The Prokaryotes, vol. 1, pp. 390-399. Edited by M. P. Starr, H. Stolp, H. G. Trüper, A. Balows \& H. G. Schlegel. New York: Springer. 
Larkin, J. M. (1989). Family Simonsiellaceae Steed 1962, $615^{\mathrm{AL}}$. In Bergey's Manual of Systematic Bacteriology, vol. 3, p. 2107. Edited by J. T. Staley, M. P. Bryant, N. Pfennig \& J. G. Holt. Baltimore: Williams \& Wilkins.

Mesbah, M., Premachandran, U. \& Whitman, W. B. (1989). Precise measurement of the $\mathrm{G}+\mathrm{C}$ content of deoxyribonucleic acid by high-performance liquid chromatography. Int J Syst Bacteriol 39, 159-167.

Morse, S. A. \& Knapp, J. S. (1991). The genus Neisseria. In The Prokaryotes, vol. 3, pp. 2496-2529. Edited by A. Balows, H. G. Trüper, M. Dworkin, K. Harder \& K.-H. Schleifer. New York: Springer.

Moss, M. O. \& Bryant, T. N. (1982). DNA:rRNA hybridization studies of Chromobacterium fluviatile. J Gen Microbiol 128, 829-834.

Nishimura, Y., Kinpara, M. \& lizuka, H. (1989). Mesophilobacter marinus gen. nov., sp. nov.: an aerobic coccobacillus isolated from seawater. Int J Syst Bacteriol 39, 378-381.

Page, R. D. M. (1996). TREEVIEW: an application to display phylogenetic trees on personal computers. Comput Appl Biosci 12, 357-358.

Patureau, D., Godon, J.-J., Dabert, P., Bouchez, T., Bernet, N., Delgenes, J. P. \& Moletta, R. (1998). Microvirgula aerodenitrificans gen. nov., sp. nov., a new Gram-negative bacterium exhibiting corespiration of oxygen and nitrogen oxides up to oxygen-saturated conditions. Int J Syst Bacteriol 48, 775-782.

Pearson, W. R. (1994). Using the FASTA program to search protein and DNA sequence databases. Methods Mol Biol 24, 307-331.

Rasmussen, S. W. (1995). DNATools, a software package for DNA sequence analysis. Copenhagen: Carlsberg Laboratory.
Rossau, R., Van Landschoot, W., Mannheim, W. \& De Ley, J. (1986). Inter- and intrageneric similarities of ribosomal ribonucleic acid cistrons of the Neisseriaceae. Int J Syst Bacteriol 36, 323-332.

Rossau, R., Vandenbussche, G., Thielemans, S., Segers, P., Grosch, H., Göthe, E., Mannheim, W. \& De Ley, J. (1989). Ribosomal ribonucleic acid cistron similarities and deoxyribonucleic acid homologies of Neisseria, Kingella, Eikenella, Simonsiella, Alysiella, and Centers for Disease Control groups EF-4 and M-5 in the emended family Neisseriaceae. Int J Syst Bacteriol 39, 185-198.

Saitou, N. \& Nei, M. (1987). The neighbor-joining method: a new method for reconstructing phylogenetic trees. Mol Biol Evol 4, 406-425.

Snell, J. J. S. (1984). Genus IV. Kingella Henriksen and Bøvre 1976, $449^{\mathrm{AL}}$. In Bergey's Manual of Systematic Bacteriology, vol. 1, pp. 307309. Edited by N. R. Krieg \& J. G. Holt. Baltimore: Williams \& Wilkins.

Vedros, N. A. (1984). Genus I. Neisseria Trevisan $1885,105^{\mathrm{AL}}$. In Bergey's Manual of Systematic Bacteriology, vol. 1, pp. 290-296. Edited by N. R. Krieg \& J. G. Holt. Baltimore: Williams \& Wilkins.

Wong, J. D. \& Janda, J. M. (1992). Association of an important Neisseria species, Neisseria elongata subsp. nitroreducens, with bacteremia, endocarditis, and osteomyelitis. J Clin Microbiol 30, 719-720.

Yeruham, I., Perl, S. \& Elad, D. (2001). Infectious bovine keratoconjunctivitis and lymphofollicular hyperplasia of the third eyelid in heifers. J Vet Med B Infect Dis Vet Public Health 48, 137-141.

Yuen, K. Y., Woo, P. C., Teng, J. L., Leung, K. W., Wong, M. K. \& Lau, S. K. (2001). Laribacter hongkongensis gen. nov., sp. nov., a novel gram-negative bacterium isolated from a cirrhotic patient with bacteremia and empyema. J Clin Microbiol 39, 4227-4232. 